\title{
Effect of Bcl-2-siRNA on proliferation and apoptosis of pediatric acute B lymphoblastic leukemia (A-BLL) cells
}

\author{
W.B. Meng ${ }^{1}$, J.P. Liu' ${ }^{2}$ X.W. Wang ${ }^{2}$ and L.H. E ${ }^{3}$ \\ 1'Department of Obstetrics and Gynecology, \\ Affiliated Hospital of Inner Mongolia Medical University, Hohhot, China \\ ${ }^{2}$ Department of Pediatric Hematology, \\ Inner Mongolia People's Hospital, Hohhot, China \\ ${ }^{3}$ Department of Stomatology, \\ Affiliated Hospital of Inner Mongolia Medical University, Hohhot, China \\ Corresponding authors: W.B. Meng / L.H. E \\ E-mail: 349881704@qq.com / wangxwdph@yeah.net \\ Genet. Mol. Res. 14 (4): 12427-12436 (2015) \\ Received May 3, 2015 \\ Accepted July 29, 2015 \\ Published October 16, 2015 \\ DOI http://dx.doi.org/10.4238/2015.October.16.9
}

\begin{abstract}
This study analyzed the effect of small interfering RNA specific for the $B C l$-2 gene (siRNA Bcl-2) on the proliferation and chemotherapeutic sensitivity of pediatric $A-B L L$ cells. Marrow samples were obtained from sixty newly-diagnosed A-BLL pediatric patients. The Bcl-2 mRNA expression in these samples was quantified by real time polymerase chain reaction. The $B c l-2$ mRNA re-expression was analyzed by RNA interference using $B c l-2-s i R N A$. Cellular proliferation was detected using the MTT (Thiazolyl Blue Tetrazolium Bromide) assay. The cell apoptosis was quantified by flow cytometry. The $\mathrm{Bcl}-2$ mRNA expression was significantly higher in the drug-resistance group than in the chemotherapy sensitivity group prior to chemotherapy $(P<0.05)$. In addition, the $B c l-2$ mRNA expression in the chemotherapy sensitivity group was significantly higher before chemotherapy than that after chemotherapy $(P<0.05)$. The $B c l-2$ mRNA expression significantly decreased in the leukemic cells of the Bcl-2-siRNA
\end{abstract}


transfection group. We observed statistically significant differences in the relative mRNA expression levels among the Bcl-2-siRNA transfection, blank control, liposome empty transfection, and unrelated sequence oligonucleotide groups $(P<0.05)$. The rate of apoptosis in pediatric $A-B L L$ leukemic cells was observed to increase significantly after transfection with Bcl-2-siRNA compared to the control, liposome empty transfection, and unrelated sequence oligonucleotide groups $(P<0.05)$. Therefore, we concluded that $\mathrm{Bcl}-2-$ siRNA can successfully inhibit the multiplicative capacity of A-BLL leukemic cells and promote apoptosis.

Key words: Bcl-2-siRNA gene; Cell proliferation; Cell apoptosis; Pediatric acute B lymphocytic leukemia

\section{INTRODUCTION}

The B-cell lymphoma/leukemia-2 (Bcl-2) gene is closely associated with apoptosis and tumor incidence and progression. It is a critical regulatory factor for apoptosis, and has been the subject of widespread attention. Its anti-apoptotic effect plays an important role in the incidence of apoptosis (Kaparou et al., 2013). It is also associated with the incidence of malignant tumor, and determines the applicability of the specific chemotherapeutic drugs based on tumor prognosis (Wang et al., 2014). Acute B lymphocytic leukemia (A-BLL) is the most common pediatric acute leukemia with a high rate of fatality; A-BLL is known to severely threaten the life of pediatric patients (Singh et al., 2011). So far, its specific pathogenesis remains unclear. A few recent reports have indicated a correlation between $\mathrm{Bcl}-2$ expression and drug resistance of clinical chemotherapy for pediatric A-BLL.

The expression of the $\mathrm{Bcl}-2$ gene in leukemic tumor cells can be reduced and apoptosis of the leukemic cells can be promoted by interrupting the $\mathrm{Bcl}-2$ gene during transcription and translation (Chaber et al., 2013). Therefore, the mRNA of the Bcl-2 gene can be targeted through the synthesized small interefering RNA (siRNA), thereby interrupting the translation and reducing the expression of the Bcl-2 gene (Vazquez-Franco et al., 2012). Bcl-2 plays an important role in the incidence, progression, and drug resistance of pediatric A-BLL (Amirghofran et al., 2011). Therefore, in this study, siRNA specific for Bcl-2 mRNA was designed and synthesized, and the effect of $B c /-2-s i R N A$ on the proliferation and apoptosis of pediatric A-BLL cells was determined via RNA interference.

\section{MATERIAL AND METHODS}

\section{Subjects}

Sixty A-BLL pediatric patients aged between 1 and 18 years (average 8.7 years; 26 male and 24 female patients) newly diagnosed at the Affiliated Hospital of Inner Mongolia Medical University between January 2013 and June 2014 were tested in this study. A definite diagnosis was made based on the results of cytomorphological, immunophenotype, and molecular biological diagnostic criteria. The A-BLL-positive patients tested positive for CD79a, CDI9, CD10, and HLADR and negative for Smlg and Cylg via flow cytometry. The pediatric patients were subjected 
to the vincristine, daunorubicin, L-asparaginase, and dexamethasone (VDCD) chemotherapeutic regimen recommended by the Chinese Children's Leukemia Group. Marrow was collected from all patients before and after chemotherapy.

\section{Grouping criterion}

The remission criterion was in accordance with the diagnosis and treatment criterion presented by the Hematology Group of the Pediatrics Branch of the Chinese Medical Association. The patients in complete remission were sensitive to chemotherapy and the patients not meeting the complete remission criterion were deemed to be chemotherapy-resistant (Amirghofran et al., 2009).

\section{Materials and reagents}

The INTERFERin kits were purchased from Ruixianghe Biotechnology (Beijing, China). The Annexin V-fluorescein isothiocyanate (FITC)/propidium iodide (PI) double-staining apoptosis detection kits were purchased from Sigma-Aldrich (St. Louis, MO, USA). TRIzol reagent was purchased from ComWin Biotech Co., Ltd. (Beijing, China). Real time PCR Master Mix was purchased from Invitrogen (Carlsbad, CA, USA). Dimethyl sulfoxide (DMSO) and MTT were purchased from Boyan Biotechnology Co., Ltd (Shanghai, China). Reverse transcription reagents and the dNTP mix were purchased from Bioleaf Biotech Co., Ltd. (Shanghai, China). Taq DNA polymerase was purchased from Fermentas (MBI Fermentas, MA, USA). The DNA marker was purchased from the Amresco (Solon, OH, USA). All primers were purchased from Weijing Biotech Co., Ltd. (Shanghai, China).

The flow cytometer was purchased from Labnet International Inc. (Edison, NJ, USA), while the UV-2000 ultraviolet analyzer was purchased from Heraeus (Hanau, Germany). The constantcurrent and constant-voltage electrophoresis apparatus was purchased from Thermo-Scientific Fisher (Waltham, MA, USA). The tabletop high-speed centrifuge was purchased from Jingli Centrifuge Co., Ltd. (Beijing, China). The $-70^{\circ} \mathrm{C}$ ultra low temperature refrigerator was purchased from Medica Corporation (Bedford, MA, USA). The PCR amplifier was purchased from Hach (Loveland, CO, USA).

\section{Cell culture}

The leukemic cells were collected and centrifuged at $157 \mathrm{rcf}(\mathrm{g})$ for $5 \mathrm{~min}$. This was pipetted well to obtain a cell suspension after the addition of $1 \mathrm{X}$ phosphate buffered saline (PBS). One hundred microliter of the cell suspension and $100 \mu \mathrm{L}$ Evans blue were added to the centrifuge tube and mixed well. The solution was allowed to sit overnight. Several droplets of the staining solution were pipetted and added to the counting chamber along the edge of the cover slip, in order to fill the gap between the counting plate and the cover slip. The cell body was observed under the microscope to be complete, transparent, and unstained. The cell suspension was diluted to the desired concentration (determined based on the experiment objective) after determining the cell concentration by counting.

\section{Culture of leukemic cells and transfection of synthesized siRNA}

RPMI-1640 medium (KEYGEN, Nanjing, China) containing 10\% fetal bovine serum, penicillin $(100 \mathrm{U} / \mathrm{ml})$, and streptomycin $(100 \mathrm{U} / \mathrm{ml})$ was added to a 24-well microplate filled with 
leukemic cells. The cells were cultured in an incubator containing $5 \% \mathrm{CO}_{2}$ at $37^{\circ} \mathrm{C}$, until a cell coverage rate of $50 \%$ was achieved. The culture solution was pipetted. The cells were then washed once with the RPMI-1640 culture medium without penicillin, streptomycin, or fetal bovine serum. The cells were divided into the blank control, liposome empty transfection, unrelated sequence oligonucleotide, and $\mathrm{Bcl}$-2-siRNA groups. The cells were then prepared using the INTERFERin kit, as per the manufacturer protocols.

\section{Detection of $\mathrm{Bcl}-2$ mRNA}

Total DNA was extracted using TRIzol reagent, in accordance with the manufacturer instructions. The polymerase chain reaction $(\mathrm{PCR})$ solution contained the template DNA (4 $\mu \mathrm{L})$, 10X PCR reaction buffer $(5 \mu \mathrm{L}), 50 \mathrm{mM} \mathrm{MgCl}_{2}(1.5 \mu \mathrm{L}), 10 \mathrm{mM}$ dNTP mixture $(\mathrm{I} \mu \mathrm{L}), 10 \mathrm{pM}$ upstream primer $(\mathrm{I} \mu \mathrm{L}), 10 \mathrm{pM}$ downstream primer $(1 \mu \mathrm{L})$, Taq enzyme $(0.3 \mu \mathrm{L})$, and water, at a final volume of $50 \mu \mathrm{L}$. The reaction conditions were set as follows: pre-denaturation at $94^{\circ} \mathrm{C}$ for $5 \mathrm{~min}$, denaturation at $94^{\circ} \mathrm{C}$ for $30 \mathrm{~s}, 30$ cycles of annealing at $60^{\circ} \mathrm{C}$ for $30 \mathrm{~s}$, and another round of annealing at $72^{\circ} \mathrm{C}$ for $30 \mathrm{~s}$, and a final extension at $72^{\circ} \mathrm{C}$ for $10 \mathrm{~min}$. The amplification product $(10 \mu \mathrm{L})$ was electrophoresed on a $1.5 \%$ agarose gel; the results were observed, scanned, and analyzed using an ultraviolet analyzer.

\section{Detection of cell proliferation by MTT assay}

The cells were divided into control (blank), liposome empty transfection, unrelated sequence oligonucleotide, and Bcl-2-siRNA transfection groups. The leukemic cells were inoculated to a 96well microplate at a concentration of $2.0 \times 10^{8} / \mathrm{L}$ (at $100 \mu \mathrm{L} /$ well) and cultured for $48 \mathrm{~h}$. The cells were cultured for $4 \mathrm{~h}$ at $37^{\circ} \mathrm{C}$ after the removal of the culture plate; twenty microliter of the MTT solution $(5.0 \mathrm{~g} / \mathrm{L})$ was added to each well. The supernatant was pipetted out and $150 \mu \mathrm{L}$ DMSO was added to the wells. The plate was shaken well using a plate shaking table, and the absorbance (A) of each well was determined at a wavelength of $570 \mathrm{~nm}$. The result was expressed as the inhibition ratio (Gaizo Moore et al., 2008)..Computational formula for inhibition ratio:

inhibition ratio $(\%)=\frac{\text { (average A value of the control group }- \text { average A value of the experimental group) }}{\text { average A value of the control group }} \times 100 \%$

\section{Determination of apoptosis characteristics using a flow cytometer}

The Annexin V-FITC/PI kit was used to analyze apoptosis in the transfected leukemic cells. The cells were centrifuged at $2000 \mathrm{rpm}$ for $5 \mathrm{~min}$. The suspended cells were collected and washed twice with PBS. The cells were suspended with $400 \mu \mathrm{L} 1 \mathrm{X}$ binding buffer. The concentration was set to approximately $1 \times 10^{6}$ cells $/ \mathrm{mL}$. The cell suspension was shaken gently after addition of $5 \mu \mathrm{L}$ Annexin V-FITC, and incubated for $15 \mathrm{~min}$ at $2^{\circ}-8^{\circ} \mathrm{C}$. Ten microliter propidium iodide was added to the cells; the cells were incubated again for 5 min at $2^{\circ}-8^{\circ} \mathrm{C}$. The solution was detected using a flow cytometer within $1 \mathrm{~h}$. Annexin V-FITC+/PI- signifies the presence of apoptotic cells at an early stage. Formula for the apoptosis rate = number of (FITC + PI -) cells/total number of cells (High et al., 2010). 


\section{Statistical analysis}

All experimental data was statistically analyzed using the SPSS v.15.0 software platform (IBM, Armonk, NY, USA). The measurement data was expressed as mean \pm standard deviation (mean \pm SD). The data was subjected to one-way analysis of variance (ANOVA) in order to compare among multiple groups. $\mathrm{P}$ value $<0.05$ indicated statistically significant differences.

\section{RESULTS}

\section{Expression of Bcl-2 mRNA in the different groups of A-BLL pediatric patients}

The level of expression of $\mathrm{Bcl}-2$ mRNA in the drug-resistance group was (statistically) significantly higher than that in the concurrent chemotherapy sensitivity group $(P<0.05)$; the level of expression of $\mathrm{Bcl}-2$ mRNA in the chemotherapy sensitivity group was significantly higher before chemotherapy than that after chemotherapy; this difference was also statistically significant $(P<$ 0.05). On the other hand, the level of expression of $\mathrm{Bcl}-2 \mathrm{mRNA}$ in the drug-resistance group did not alter significantly before and after chemotherapy (Figures 1 and 2).

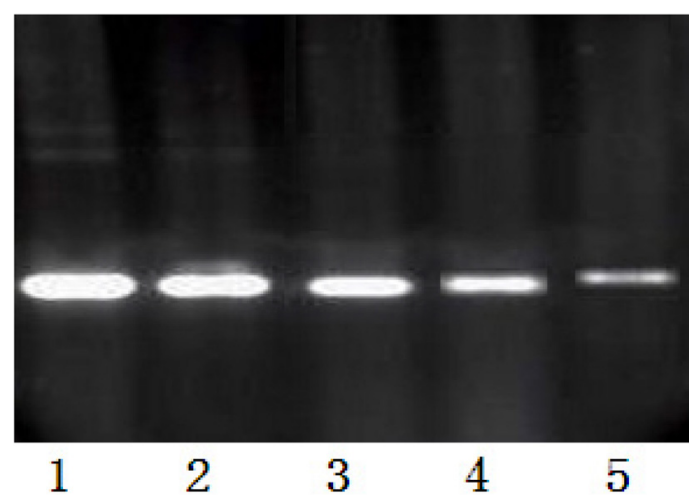

Figure 1. Expression levels of $B c l-2$ mRNA in various groups. Lane 1 = drug-resistance group before chemotherapy; lane 2 = drug-resistance group after chemotherapy; lane 3 = sensitivity group before chemotherapy; lane 4 = sensitivity group after chemotherapy; lane $5=$ control group.

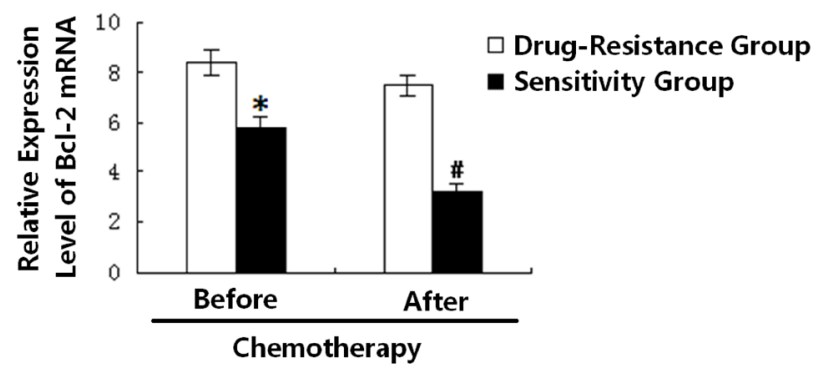

Figure 2. Comparison of relative expression levels of $B c l-2$ mRNA among various groups. The $B c l-2$ mRNA expression levels in the drug-resistance group before chemotherapy and in the concurrent chemotherapy sensitivity group were significantly different; ${ }^{*} P<0.05$. The mRNA expression levels in the chemotherapy sensitivity group before and after chemotherapy were also significantly different; ${ }^{P} P<0.05$. 


\section{Effect of $B c /-2-s i R N A$ on the expression of $B c l-2$ mRNA in pediatric A-BLL leukemic} cells

The leukemic cells of A-BLL pediatric patients were transfected with Bcl-2-siRNA. The results indicated that the $\mathrm{Bcl}-2 \mathrm{mRNA}$ expression in the leukemic cells in the Bcl-2-siRNA transfection group decreased significantly. The differences among the relative expression levels of $\mathrm{Bcl}-2 \mathrm{mRNA}$ in the $\mathrm{Bcl}-2-$-siRNA transfection, blank control, liposome empty transfection, and unrelated sequence oligonucleotide groups were not statistically significant $(P>0.05)$ (Figures 3 and 4).

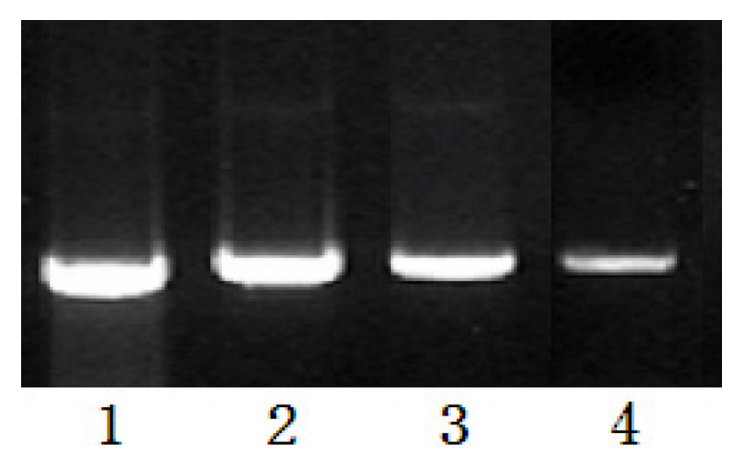

Figure 3. Effect of $B c l-2$-siRNA on the level of expression of $B c l-2$ mRNA. Lane 1 = control group; lane 2 = liposome empty transfection group; lane 3 = unrelated sequence oligonucleotide group; lane $4=B c l-2$-siRNA transfection group.



Figure 4. Differences in the levels of $B C l-2$ mRNA expression in the different transfection groups. ${ }^{*} \mathrm{P}<0.05$ compared to the Bcl-2-siRNA transfection group.

\section{Effect of Bcl-2-siRNA on the proliferative capacity of pediatric A-BLL leukemic cells}

The results of this experiment indicated that the inhibition ratios of the blank control group, liposome empty transfection group, unrelated sequence oligonucleotide group, and the Bcl-2-siRNA group were $0,8.31 \%, 13.57 \%$, and $58.42 \%$, respectively. The inhibition ratio of the Bcl-2-siRNA transfection group was significantly higher than those of the control, liposome empty transfection, and unrelated sequence oligonucleotide groups. This difference was statistically significant $(P<$ 0.05) (Figure 5). 




Figure 5. Effect of $\mathrm{BCl}-2-$ siRNA on the proliferative capacity of acute B lymphocytic leukemia (leukemic) cells. ${ }^{*} \mathrm{P}<$ 0.05 , compared to the $B c l-2-s i R N A$ transfection group.

\section{Effect of Bcl-2-siRNA on pediatric A-BLL leukemic cell apoptosis}

The results of this study indicated that the apoptosis rates of the blank control, liposome empty transfection, unrelated sequence oligonucleotide, and $\mathrm{BCl}-2$-siRNA groups were $2.37 \pm 0.82$, $3.86 \pm 1.52,6.94 \pm 1.83$, and $37.91 \pm 5.22$, respectively. The apoptosis rate of the pediatric A-BLL leukemic cells was significantly higher than those of the control, liposome empty transfection, and unrelated sequence oligonucleotide groups $(P<0.05)$ (Figure 6).

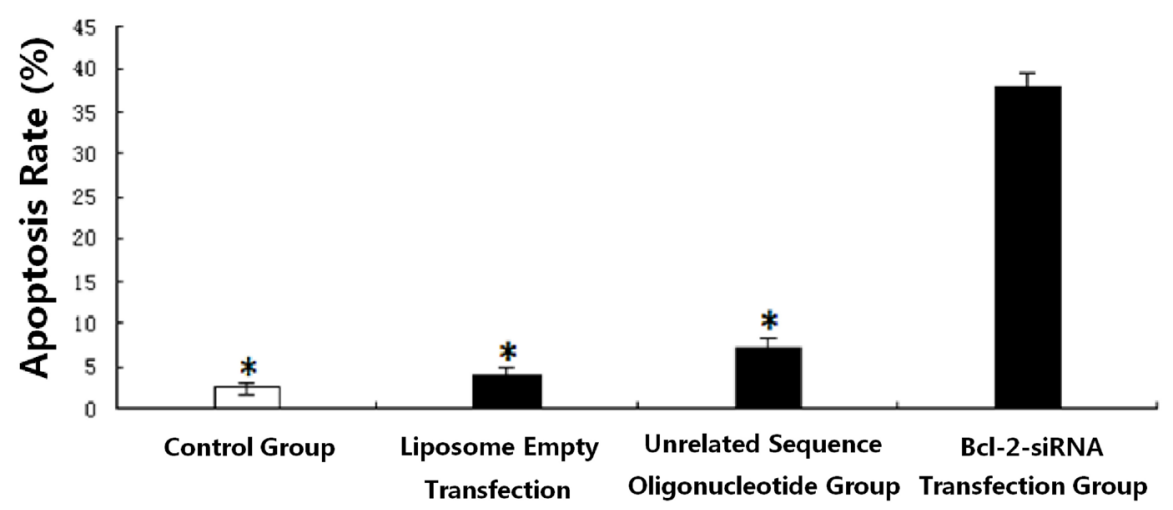

Figure 6. Effect of $B c l-2$-siRNA on the apoptosis capacity of A-BLL leukemic cells. ${ }^{*} \mathrm{P}<0.05$, compared to the $B c /-2$ SiRNA transfection group.

\section{DISCUSSION}

Acute B lymphocytic leukemia (A-BLL) is the most common pediatric neoplastic disease, wherein the $\mathrm{B}$ lymphocytic cell clones proliferate abnormally, the normal hematopoietic components in the marrow are replaced by leukemic cells, and the leukemic cells spread through blood and affect the tissues and organs outside of the marrow (such as liver, spleen, and lymph node), thereby causing the corresponding clinical manifestations and severely threatening the life of pediatric 
patients (high fatality rate) (Gupta et al., 2013; Avila et al., 2014; Morais et al., 2014). Radioactive rays, and chemicals, viruses, and genetic factors are known to trigger leukemia. In addition, adhesives, coating, and floor covering, which are used in decoration, release toxic substances, such as formaldehyde, lead, and benzene, which severely damage the hemopoietic system of the human body. This is an important cause leading to a high incidence of childhood leukemia over the past few years (Liu et al., 2014; Pana et al., 2014; Petersen et al., 2014). The VDLD therapeutic regime that has been used clinically is the first-line approach for treatment of A-BLL. However, recent research has indicated an increase in the rate of resistance to chemotherapeutic drugs; in addition, these drugs impart severe toxic and side effects, thereby restricting the clinical use of this therapeutic regime (Brackett et al., 2014; Melachuri et al., 2014).

In this study, we tested the changes in the expression of the $\mathrm{Bcl}-2$ gene before and after chemotherapy, divided the clinical A-BLL pediatric patients into the sensitivity and drug-resistant groups for analysis, and compared the differences in expression in different groups of pediatric patients suffering from A-BLL between January 2013 and June 2014. The results of this study have indicated that the A-BLL pediatric patients in the drug-resistance group show significantly higher Bcl-2 mRNA expression, compared to those in the chemotherapy sensitivity group. In addition, the $\mathrm{Bcl}-2$ mRNA expression in the A-BLL pediatric patients classified into the chemotherapy sensitivity group decreased significantly after chemotherapy, while the expression of $B c l-2$ mRNA in the A-BLL pediatric patients in the chemotherapy drug-resistance group did not alter significantly before and after chemotherapy. A literature review revealed that $\mathrm{Bcl}-2$ may be an important factor affecting the incidence, progression, and prognosis of pediatric A-BLL; in addition, high Bcl-2 expression may be a leading cause for chemotherapeutic drug resistance in leukemic cells, and may affect the therapeutic potential of the drug (Brumatti et al., 2013; Hitzler et al., 2014; Liu et al., 2014). However, further research must be conducted to demonstrate the involvement of $\mathrm{Bcl}-2$, and specifically define the roles and mechanism of $\mathrm{Bcl}-2$ in incidence, progression, and drug-resistance of pediatric A-BLL.

The emergence of advanced techniques, such as gene cloning and sequencing, and the rapid development and maturity of the RNA interference technique, has led to the focus on siRNA (designed for a specific target gene) as the new breakthrough for the treatment of various diseases, including cancers, at the molecular level (Park et al., 2013; Vitagliano et al., 2013). Moreover, RNA interference, a gene therapy-based treatment method, has many advantages, including a high specificity, high biological activity, high efficiency, low toxicity, and high safety, compared to the traditional treatment methods. Therefore, it has been subjected to increasing attention by researchers throughout the world (Patel et al., 2014).

The $\mathrm{Bcl}-2$ gene, which is a potential inhibitor regulating apoptosis, can inhibit or block apoptosis resulting from several factors (Davids et al., 2013; Samuel et al., 2013). Inhibition of $\mathrm{Bcl}-2$ gene expression in malignant tumors could promote apoptosis in tumor cells. Therefore, a siRNA was designed to specifically inhibit the expression of the Bcl-2 gene via RNA interference. This can be used to inhibit the growth of tumors expressing a high level of the $\mathrm{Bcl}-2$ gene (Kaparou et al., 2013). Current RNA interference research on the $\mathrm{Bcl}-2$ gene has successfully improved the sensitivity of many drug-resistant tumors to radiotherapy and chemotherapy, as well as the prognosis of tumor patients. The Bcl-2 siRNA can inhibit tumor growth and reverse drug-resistance arising from high $\mathrm{Bcl}-2$ expression. Previous research has demonstrated that RNA interference has a good therapeutic effect (Lagadinou et al., 2013; Takahashi et al., 2013) on non-Hodgkin's lymphoma (among hematological tumors). In addition, it has been shown to exhibit a high level of safety and efficacy, without any toxic or side effects (Ishitsuka et al., 2012). 
However, the expression of $\mathrm{BCl}-2$ in pediatric A-BLL remains to be quantified; in addition, the effect of RNA interference on resistance to chemotherapeutic drugs against leukemia remains to be investigated. Based on the results of previous research, the authors utilized RNA interference to transfect $B C l-2-s i R N A$ into the leukemic cells of pediatric patients with A-BLL in this study. In addition, an experimental model was successfully designed to further demonstrate that $B c l-2-s i R N A$ significantly reduces the proliferative capacity of pediatric A-BLL leukemic cells and increases the apoptosis rate. Moreover, this study suggested that $B c l-2-s i R N A$ can inhibit the proliferation of tumor cells, and induce apoptosis in tumor cells.

\section{Conflicts of interest}

The authors declare no conflict of interest.

\section{REFERENCES}

Amirghofran Z. Daneshbod $\mathrm{Y}$ and Gholijani N (2009). Bcl-2 in combination to myeloid antigen expression in adult acute lymphoblastic leukemia and prognostic outcome. Oncol. Res. 17: 447-454.

Amirghofran Z, Daneshbod Y, Gholjiani N and Esmaeilbeig M (2011). The influence of Bcl-2 and myeloid antigen expression on response to therapy in childhood acute lymphoblastic leukemia. Arch. Iran Med. 14: 170-174.

Avila ML, Macartney CA, Hitzler JK, Williams S, et al. (2014). Assessment of the outcomes associated with periprocedural anticoagulation management in children with acute lymphoblastic leukemia. J. Pediatr. 164: 1201-1207.

Brackett J, Schafer ES, Leung Dh and Bernhardt MB (2014). Use of allopurinol in children with acute lymphoblastic leukemia to reduce skewed thiopurine metabolism. Pediatr. Blood Cancer 61: 1114-1117.

Brumatti G, Salmanidis M, Kok CH, Bilardi RA, et al. (2013). HoxA9 regulated Bcl-2 expression mediates survival of myeloid progenitors and the severity of HoxA9-dependent leukemia. Oncotarget 4: 1933-1947.

Chaber R, Fiszer-Maliszewska L, Noworolska-Sauren D, Kwasnicka J, et al. (2013). The BCL-2 protein in precursor B acute lymphoblastic leukemia in children. J. Pediatr. Hematol. Oncol. 35: 180-187.

Davids MS, Letai A and Brown JR (2013). Overcoming stroma-mediated treatment resistance in chronic lymphocytic leukemia through BCL-2 inhibition. Leuk. Lymphoma 54: 1823-1825.

Del Gaizo Moore V, Schlis KD, Sallan SE, Armstrong SA, et al. (2008). BCL-2 dependence and ABT-737 sensitivity in acute lymphoblastic leukemia. Blood 111: 2300-2309.

Gupta A, Jain S, Agarwal C and Kapoor G (2013). Successful outcome of mucormycosis in two children on induction therapy for acute lymphoblastic leukemia. Indian J. Med. Paediatr. Oncol. 34: 313-316.

High LM, Szymanska B, Wilczynska-Kalak U, Barber N, et al. (2010). The Bcl-2 homology domain 3 mimetic ABT-737 targets the apoptotic machinery in acute lymphoblastic leukemia resulting in synergistic in vitro and in vivo interactions with established drugs. Mol. Pharmacol. 77: 483-494.

Hitzler JK, He W, Doyle J, Cairo M, et al. (2014). Outcome of transplantation for acute lymphoblastic leukemia in children with Down syndrome. Pediatr. Blood Cancer 61: 1126-1128.

Ishitsuka K, Kunami N, Katsuya H, Nogami R, et al. (2012). Targeting Bcl-2 family proteins in adult T-cell leukemia/lymphoma: in vitro and in vivo effects of the novel Bcl-2 family inhibitor ABT-737J. Cancer Lett. 317: 218-225.

Kaparou M, Choumerianou D, Perdikogianni C, Matimianaki G, et al. (2013). Enhanced levels of the apoptotic BAX/BCL-2 ratio in children with acute lymphoblastic leukemia and high-risk features. Genet. Mol. Biol. 36: 7-11.

Lagadinou ED, Sach A. Callahan K, Rossi RM, et al. (2013). BCL-2 inhibition targets oxidative phosphorylation and selectively eradicates quiescent human leukemia stem cells. Cell Stem Cell 12: 329-341.

Liu HC, Yeh TC, Hou JY, Chen KH, et al. (2014). Triple intrathecal therapy alone with omission of cranial radiation in children with acute lymphoblastic leukemia. J. Clin. Oncol. 32: 1825-1829.

Liu J, Yao Y, Ding H and Chen R (2014). Oxymatrine triggers apoptosis by regulating Bcl-2 family proteins and activating caspase-3/caspase-9 pathway in human leukemia HL-60 cells. Tumour Biol. 35: 5409-5415.

Melachuri S, Gandrud L and Bostrom B (2014). The association between fasting hypoglycemia and methylated mercaptopurine metabolites in children with acute lymphoblastic leukemia. Pediatr. Blood Cancer 61: 1003-1006.

Morais EF, Lira JA, Macedo RA, Santos KS, et al. (2014). Oral manifestations resulting from chemotherapy in children with acute lymphoblastic leukemia. Braz. J. Otorhinolaryngol. 80: 78-85. 
Pana ZD, Samarah F, Papi R, Antachopaulos C, et al. (2014). Mannose binding lectin and ficolin-2 polymorphisms are associated with increased risk for bacterial infections in children with B acute lymphoblastic leukemia. Pediatr. Blood Cancer 61: 1017-1022.

Park HS, Hwang HJ, Kim GY, Cha HJ, et al. (2013). Induction of apoptosis by fucoidan in human leukemia U937 cells through activation of p38 MAPK and modulation of Bcl-2 family. Mar. Drugs 11: 2347-2364.

Patel V, Chen LS, Wierda WG, Balakrishnan K, et al. (2014). Impact of bone marrow stromal cells on Bcl-2 family members in chronic lymphocytic leukemia. Leuk. Lymphoma 55: 899-910.

Petersen WC Jr, Clark D, Senn SL, Cash WT, et al. (2014). Comparison of allergic reactions to intravenous and intramuscular pegaspargase in children with acute lymphoblastic leukemia. Pediatr. Hematol. Oncol. 31: 311-317.

Samuel S, Beljanski V, Van Grevenynghe J, Richards S, et al. (2013). BCL-2 inhibitors sensitize therapy-resistant chronic lymphocytic leukemia cells to VSV oncolysis. Mol. Ther. 21: 1413-1423.

Singh A, Jayanthan A, Farran A, Elwi AN, et al. (2011). Induction of apoptosis in pediatric acute lymphoblastic leukemia (ALL) cells by the therapeutic opioid methadone and effective synergy with Bcl-2 inhibition. Leuk. Res. 35: 1649-1657.

Takahashi M, Elbarbary RA, Nakashima A, Abe M, et al. (2013). A naked RNA heptamer targeting the human Bcl-2 mRNA induces apoptosis of HL60 leukemia cells. Cancer Lett. 328: 362-368.

Vazquez-Franco JE, Reyes-Maldonado E, Vela-Ojeda J, Dominquez-Lopez ML, et al. (2012). Src, Akt, NF-kappaB, BCL-2 and C-IAP1 may be involved in an anti-apoptotic effect in patients with BCR-ABL positive and BCR-ABL negative acute lymphoblastic leukemia. Leuk. Res. 36: 862-867.

Vitagliano O, Addeo R, D'Angelo V, Indolfi C, et al. (2013). The Bcl-2/Bax and Ras/Raf/MEK/ERK signaling pathways: implications in pediatric leukemia pathogenesis and new prospects for therapeutic approaches. Expert Rev. Hematol. 6: 587-597.

Wang SM, Sun LL, Zeng WX, Wu WS, et al. (2014). Effects of a microRNA binding site polymorphism in SLC19A1 on methotrexate concentrations in Chinese children with acute lymphoblastic leukemia. Med. Oncol. 31: 62-68. 